\title{
Weekly cholecalciferol supplementation results in significant reductions in infection risk among the vitamin D deficient: results from the CIPRIS pilot RCT
}

Steve Simpson $\mathrm{Jr}^{1 *}$, Ingrid van der Mei ${ }^{1}$, Niall Stewart ${ }^{2,3}$, Leigh Blizzard ${ }^{1}$, Prudence Tettey ${ }^{1}$ and Bruce Taylor ${ }^{1}$

\begin{abstract}
Background: Observational studies suggest vitamin D deficiency may contribute to the risk of acute infections. We undertook a randomised controlled trial $(\mathrm{RCT})$ of cholecalciferol supplementation as an intervention against acute infections.

Methods: A cohort of 34 healthy adults was randomised to 20,000 IU/week cholecalciferol or identical placebo and followed for 17 weeks during winter 2012. Acute infections, defined as the occurrence of sustained (at least an hour) infection symptoms, either of severity $2 / 5$ or greater or sustained over $24 \mathrm{~h}$, were monitored by daily online symptom reporting, with potential infections assessed in clinic. No microbiological verification of symptoms was available, however. Primary endpoint was the occurrence of acute infection; secondary endpoints were infection duration and infection severity; and tertiary endpoints were change in serum 25 -hydroxyvitamin $\mathrm{D}(25(\mathrm{OH}) \mathrm{D})$ and adverse events.

Results: No treatment effect was observed for infection risk (HR: 0.83, $95 \% \mathrm{Cl}: 0.53,1.31$ ), nor duration or severity. However, on stratification by baseline serum 25(OH)D (levels chosen on the basis of average levels in our cohort and known minimums needed for bone health), a significant treatment effect on infection risk was evident among those who were vitamin $D$ deficient at the start of the study, such that those of baseline $25(\mathrm{OH}) \mathrm{D}<40 \mathrm{nmol} / \mathrm{L}$ $(n=4)$ realised a $44 \%$ reduction in infection risk (HR: $0.56 ; 95 \% \mathrm{Cl}: 0.32,0.96 ; P=0.007)$, this increasing to $73 \%$ on restriction to clinically verified infections (HR: $0.27 ; 95 \% \mathrm{Cl}: 0.07,1.00 ; P=0.050)$. A similar but less consistent and nonsignificant effect was seen for infection severity. Treatment was associated with significantly higher $25(\mathrm{OH}) \mathrm{D}$ compared to placebo; however, the maximum 25(OH)D was $154 \mathrm{nmol} / \mathrm{L}$ and no adverse events occurred.
\end{abstract}

Conclusions: The results of this study suggest a protective effect of vitamin D supplementation against acute infection risk among persons who are vitamin D deficient. Larger studies are needed to validate these findings.

Keywords: Vitamin D, Acute infection, Randomised controlled trial

\footnotetext{
* Correspondence: steve.simpson@utas.edu.au

${ }^{1}$ Menzies Institute for Medical Research, University of Tasmania, 17 Liverpool

Street, Hobart, TAS, Australia

Full list of author information is available at the end of the article
} 


\section{Background}

Acute infections, particularly respiratory tract infections (RTIs), are a major cause of mortality, particularly among those at the extremes of age and those requiring significant support $[1,2]$. Moreover, RTIs are among the most frequent sources of absenteeism from work and school, accounting for millions of lost work and school days and billions of lost wages each year [3]. Thus, an intervention to reduce the frequency of acute infections is indicated.

A significant modulator of the immune response is vitamin D's active metabolite, 1,25-dihydroxyvitamin D, which has been shown to regulate antimicrobial peptides that comprise a significant part of the innate immune response and is known to modulate the expression of nearly 1,000 genes $[4,5]$. In persons who are vitamin D deficient, as occurs in winter at high latitudes and year-round for long-term medical inpatients [6,7], there is a potential for significant dysfunction in the innate immune response, leading to a greater frequency of infections.

This has been supported by observational studies, which found a potent relationship between vitamin D deficiency and acute infection [8-13]. Randomised controlled trials (RCTs) of cholecalciferol supplementation have had mixed results, however, with some finding protective treatment effects [14-17] and others not [18-20], reflecting in part varied methodologies. Recently, Murdoch and colleagues ran a 2-year trial of monthly cholecalciferol supplementation for 18 months in 322 healthy adults, with comprehensive monitoring of infections and clinical assessment, but finding no difference in infection occurrence, duration or severity [20]. Despite some null findings, systematic reviews [21,22] have indicated a potential protective effect against infections from vitamin D supplementation.

We hypothesised that by improving the vitamin D sufficiency of participants, their innate immune response would more effectively clear pathogens prior to their establishing a solid colonisation, reducing the occurrence of symptomatic infections. Therefore, we undertook a pilot RCT of 20,000 IU/week cholecalciferol vs. placebo in a cohort of 34 adults to evaluate its efficacy at reducing the frequency, duration and severity of acute infections.

\section{Methods}

\section{Recruitment and follow-up}

CIPRIS (Cholecalciferol Intervention to Prevent Respiratory Infections Study) was a double-blind randomised placebo-controlled trial of 20,000 IU/week cholecalciferol supplementation, undertaken in Hobart, Australia (latitude $42.9^{\circ} \mathrm{S}$ ). This dose was chosen with a goal to give the equivalent of roughly 3,000 IU per day to realise a replete $25(\mathrm{OH}) \mathrm{D}$ status. The study was registered at www.clinical trials.gov (NCT01549938) and the Australia-New Zealand Clinical Trials Register (ACTRN12612000054819). The study was approved by the Southern Tasmania Human Research Ethics Committee, conforming to the principles embodied in the Declaration of Helsinki. All participants provided written informed consent. The study protocol was developed and finalised prior to the start of recruitment. No alterations to protocol were made during the study recruitment or follow-up periods.

Study methods, results and interpretations thereof are presented as per the CONSORT guidelines (Additional files 1 and 2).

Participants were recruited from the student and staff and their friends and families of the Menzies Research Institute Tasmania and the University of Tasmania School of Medicine, the Royal Hobart Hospital and the TasTAFE Campbell Street Campus, all essentially healthy controls representative of the general population. All clinics were conducted at the Menzies Research Institute Tasmania, however. Recruitment was in March-June 2012 conducted via flyers, email invitation and word-ofmouth communication. Exclusion criteria were 1) age $<18$ or >60 years; 2) using immunomodulatory medication; 3) diagnosed with an autoimmune, immune-deficiency or chronic respiratory condition; 4) diagnosis of hypercalcemia or malabsorption syndrome, or any parathyroid, liver or kidney disorder; 5) using vitamin D supplements (>1,000 IU/day) in the preceding 3 months; 6) being pregnant or planning to so within the study period; 7) inability to swallow capsules; or 8) inability to provide informed consent. Interested persons were invited to complete an online assessment questionnaire querying the exclusion criteria, with acceptable participants asked to provide contact information for the study investigators to contact them on. Of the 173 persons who accessed the assessment questionnaire, 52 were ineligible and 89 either did not provide contact information or declined to participate on discussing the study protocol, leaving 32 participants.

Follow-up was during the winter months, from May to October 2012, much of which is when ambient UV is too low to generate vitamin D [7].

At baseline assessment, participants were queried for demographic information and diet and behaviour affecting infection or vitamin D. At weekly updates, participants were queried about changes in health status, medication, supplements, health status, or time outside or physical activity.

Participants were also queried whether they had travel out of the state in the interval since the last weekly update. Excluding these people did not materially affect any analyses (data not shown).

Sample size for this pilot was set at 32 to allow a balance between treatment arms, with the number selected to test methods and principals in anticipation of a larger study. Participants were a convenience sample of healthy 
adults and did not represent any groups at risk of vitamin D deficiency or infection susceptibility.

\section{Randomisation and treatment}

Participants were randomised simply 1:1 to parallel treatment using a computerised randomisation program (www.randomization.com), using the first generator. A person outside the study was asked to run the randomisation and to affix the treatment labels with study IDs to the respective bottles of treatment and placebo.

Cholecalciferol and placebo capsules were obtained from Dartnells Pharmacy in Victoria, Australia. Both cholecalciferol and placebo were identical white capsules. Treatment allocations were dispensed at weekly clinics.

\section{Blinding}

As a double-blind RCT, all CIPRIS staff (including nurses and database entry personnel), investigators and participants were blinded to treatment allocation until the conclusion of follow-up.

\section{Biological specimens}

At each monthly review, a blood sample was taken from participants for measuring $25(\mathrm{OH}) \mathrm{D}$. The first two monthly specimens were also tested for corrected calcium and phosphate. Blood samples were centrifuged and the serum aliquoted and stored at $-80^{\circ} \mathrm{C}$ until analysis.

\section{Biological assays}

Serum corrected calcium and phosphate were assessed using standard methods by the Pathology Department of the Royal Hobart Hospital each week.

After the conclusion of the study, serum 25(OH)D was assessed by tandem mass spectroscopy by Canterbury Health Laboratories in New Zealand.

\section{Infection assessment}

Participants completed daily online questionnaires querying the occurrence and magnitude $(0-5$, where 0 is no presence of that symptom and 5 is most severe) of acute infection symptoms, including respiratory, gastrointestinal, urinary tract, eye, ear, skin and cold sore infections, as well as nonspecific symptoms. Online questionnaire responses were monitored each day by the chief investigator. When a participant reported symptoms of magnitude greater than $2 / 5$ (thought to be of sufficient magnitude for a single day's occurrence to warrant assessment in clinic), or two successive days of symptoms of any magnitude, the participant was invited to come into clinic for objective assessment by our study nurse.

After the conclusion of the study, infection reports from daily online surveys, and from clinic assessments, were reviewed by the chief investigator and the study nurse, classifying infections and infection type. In the event of disagreement between reviewers, infection status was agreed upon by discussion. Respiratory, gastrointestinal, urinary tract, eye, skin and cold sore infections were defined by symptoms reflective of these infection types. Ear infections were defined as earache symptoms in the absence of RTI symptoms. Systemic/nonspecific infections were defined as nonspecific symptoms like fever, malaise, fatigue, headache, and/or arthromyalgia, in the absence of other infection symptom types.

Infection duration was defined from the first day of reported symptoms and concluded at the resolution of symptoms. Where infections were confluent, a judgement was made on the basis of symptoms and symptom severities as to the end of one infection and start of another.

Infection severity for each infection was evaluated in three fashions. One was to take the maximum reported infection symptom severity for that infection. We also summated the infection severity scores for all infection symptoms for each day of the infection and summated this for a total infection severity score. Finally, we averaged the daily total infection symptom severities. For RTIs, only RTI-specific symptoms were used.

While the majority of infections were seen in clinic, a subset $(11.8 \%)$ was only reported on online daily questionnaire but not seen in clinic. Sub-analyses excluding these are reported.

\section{Adverse events}

Serum collected at the first 2 months was evaluated for the levels of corrected calcium and phosphate. These reports were reviewed by an external monitor, who could terminate a participant's participation if levels exceeded safe levels.

In addition, on daily questionnaire and at weekly and infection clinics, participants were queried about the occurrence and severity (0-5) of symptoms potentially indicative of hypercalcemia or hyperphosphatemia, including excessive thirst, abnormally high urine output, change in urine colour, bone pain, groin-area pain, confusion, irritability or other neurological symptoms. Any sustained occurrence of these could have resulted in that subject's participation being stopped.

\section{Statistical analyses}

Analysis was by intention-to-treat.

Primary outcomes were time to infection. Secondary outcomes were infection severity and duration. Tertiary outcomes were change in serum $25(\mathrm{OH}) \mathrm{D}$ and the occurrence of adverse events.

Predictors of time-to-acute infection were assessed by survival analysis, using Cox proportional hazard models for repeated events [23]. All covariates satisfied the proportional hazard assumption. 
Significance of differences in study follow-up duration and inter-review interval duration were evaluated by Kruskal-Wallis rank test.

Predictors of having an infection during the study were evaluated by logistic regression.

Predictors of infection duration, infection severity and longitudinally measured $25(\mathrm{OH}) \mathrm{D}$ were assessed by multilevel mixed effects linear regression. Predictors of infection count during the study were assessed by linear regression. Predictors of baseline-measured 25(OH)D were assessed by linear regression. As the distribution of all these variables was skewed, transformation was applied as required to satisfy homoscedasticity; however, all coefficients are reported on the scale of the original value.

Where interaction was assessed, a product term containing the primary predictor and the interaction covariate was generated and included in the model.

For all instances where data was missing, analyses were restricted to persons with complete data.

All analyses were performed using STATA/SE for Windows.

\section{Results}

\section{Cohort characteristics}

We initially recruited 32 participants, the majority (23/32) attending their first clinic in the 2 weeks of the study. Two participants (both on treatment) dropped out during the study due to not being able to meet the study's schedule rigour (one after week 1 , the other after week 4), and these were replaced with an additional two participants who ran out their period of follow-up. Analyses excluding these additional two participants did not materially affect the results (data not shown).

Participants were followed for an average of 16.4 weeks. Follow-up time did not differ significantly between treatment groups (treatment: 15.7 weeks; placebo: 17.2 weeks; $P=0.10$ ). While the interval between reviews (not including infection clinics) was 7 days, there was some variation in this, with a mean interval of 7.07 days; this interval did not significantly differ between treatment groups $(P=0.77)$.

Over the course of an average follow-up, 34 participants experienced 98 infections. Of these, the majority (69.4\%) were RTIs. Virtually everyone in the cohort had at least one infection $(31 / 34,91.2 \%)$-six people had one infection, eight had two infections, seven had three infections and ten had four or more infections.

As in Table 1, the cohort was majority female, majority Australian-born and of mean age 32 years. None of the cohort characteristics were significantly different between treatment arms. A small number of participants (two on treatment, one on placebo) reported taking multivitamins, but otherwise no one was taking any supplements which might contain vitamin $D$.

\section{Predictors of infection, infection duration and severity}

Having any infection during the study was less frequent among those on treatment (OR: 0.53; 95\% CI: 0.04, 6.51), though this was not statistically significant. Infection count was lower among those on treatment (mean: 2.01; 95\% CI: $1.12,2.89$ ) than those on placebo (mean: 3.01; 95\% CI: 1.87, 4.15), though this did not reach statistical significance $(P=0.17)$. On restriction to infections seen in clinic, this difference was increased but still did not reach statistical significance $(P=0.13)$. These analyses could not be stratified by baseline-measured 25(OH)D. Overall, there was no evidence of statistically significant treatment effects on infection overall.

Hazard of infection was not significantly predicted by treatment (Table 2) nor was infection duration or infection severity by any of the measures used.

While there was no significant effect on infection hazard by treatment overall, on stratification by baseline-measured serum $25(\mathrm{OH}) \mathrm{D}$, a protective effect from treatment became evident among those who were deficient at the start of the study (Table 3). This effect was strongest on setting the threshold at $40 \mathrm{nmol} / \mathrm{L}\left(p_{\text {interaction }}=0.042\right)$, attenuating at a threshold of $50 \mathrm{nmol} / \mathrm{L}\left(p_{\text {interaction }}=0.68\right)$ and disappearing altogether at a threshold of $60 \mathrm{nmol} / \mathrm{L}\left(p_{\text {interaction }}=\right.$ $0.40)$. On restriction to infections which were seen in clinic, these trends were increased in magnitude, though of reduced significance, likely reflecting the decreased number of infections. Associations persisted on adjustment. On restriction to RTIs, trends were similar (data not shown). Importantly, any protective effect was abrogated on adjustment for extant levels of serum 25(OH)D, indicating a true effect of treatment via increasing 25(OH)D (data not shown).

On stratification by baseline-measured $25(\mathrm{OH}) \mathrm{D}$, no effect of treatment on infection duration was apparent. For infection severity, on stratification by level of baseline $25(\mathrm{OH}) \mathrm{D}$, there were inconsistent trends for the maximum infection severity score and the average daily infection severity score, but no trend was apparent for the total infection severity score (Additional file 3). Similar results were found for RTIs seen in clinic (data not shown). No associations were found for infections not seen in clinic (data not shown).

\section{Distribution and predictors of serum vitamin D}

The mean 25(OH)D at study entry was $67.9 \mathrm{nmol} / \mathrm{L}$ (SD: 23.0), with those randomised to treatment having significantly lower baseline $25(\mathrm{OH}) \mathrm{D}$ than those allocated to placebo $(60.5$ vs. $76.4, P=0.040)$. Thereafter, the mean 25(OH)D for those on treatment was $100.7 \mathrm{nmol} / \mathrm{L}$ (SD: 23.9), while that of placebo was $56.0 \mathrm{nmol} / \mathrm{L}$ (SD: 24.2) $(P<$ $0.001)$. Trends in $25(\mathrm{OH}) \mathrm{D}$ over time are shown in Figure 1.

There was a negative interaction between baselinemeasured BMI and treatment in predicting 25(OH)D, 
Table 1 Distribution of cohort characteristics, overall and between treatment allocations

\begin{tabular}{|c|c|c|}
\hline & $\begin{array}{l}\text { Placebo } \\
n=16(47.1 \%)\end{array}$ & $\begin{array}{l}\text { Treatment } \\
n=18(52.9 \%)\end{array}$ \\
\hline Total infections during the study & 54 & 44 \\
\hline \multicolumn{3}{|l|}{ Infection type } \\
\hline Respiratory tract infection & $32(59.3)$ & $36(81.8)$ \\
\hline Gastrointestinal infection & $11(20.4)$ & $5(11.4)$ \\
\hline Urinary tract infection & 0 & 0 \\
\hline Skin infection & $2(3.7)$ & 0 \\
\hline Ear infection & $1(1.9)$ & 0 \\
\hline Eye infection & 0 & $1(2.3)$ \\
\hline Cold sore & $5(9.3)$ & $2(4.6)$ \\
\hline Systemic/nonspecific & $3(5.6)$ & 0 \\
\hline \multicolumn{3}{|l|}{ Sex } \\
\hline Male & $5(31.3)$ & $9(50.0)$ \\
\hline Female & $11(68.8)$ & $9(50.0)$ \\
\hline \multicolumn{3}{|l|}{ Birthplace } \\
\hline Australia & $15(88.2)$ & $14(82.4)$ \\
\hline New Zealand & $1(5.9)$ & $1(5.9)$ \\
\hline United Kingdom & 0 & $2(11.8)$ \\
\hline Singapore & $1(5.9)$ & 0 \\
\hline \multicolumn{3}{|l|}{ BMI at baseline } \\
\hline$<18.5$ & $1(6.3)$ & 0 \\
\hline $18.5-24.9$ & $8(50.0)$ & $10(55.6)$ \\
\hline $25.0-29.9$ & $6(37.5)$ & $7(38.9)$ \\
\hline 30 or greater & $1(6.3)$ & $1(5.6)$ \\
\hline \multicolumn{3}{|l|}{ Taking any medications at baseline? } \\
\hline No & $9(56.3)$ & $9(50.0)$ \\
\hline Yes & $7(43.8)$ & $9(50.0)$ \\
\hline \multicolumn{3}{|l|}{ Taking any supplements at baseline? } \\
\hline No & $12(75.0)$ & $15(83.3)$ \\
\hline Yes & $4(25.0)$ & $3(16.7)$ \\
\hline \multicolumn{3}{|l|}{ Ever smoked? } \\
\hline No & $12(75.0)$ & $15(83.3)$ \\
\hline Yes & $4(25.0)$ & $3(16.7)$ \\
\hline \multicolumn{3}{|c|}{ How much time do you usually spend in the sun on weekends and holidays in summer? } \\
\hline$<30 \mathrm{~min} /$ day & $1(6.3)$ & $1(5.6)$ \\
\hline 30-60 min/day & $2(12.5)$ & $3(16.7)$ \\
\hline 1-2 h/day & $6(37.5)$ & $4(22.2)$ \\
\hline 2-3 h/day & $5(31.3)$ & $4(22.2)$ \\
\hline 3-4 h/day & $2(12.5)$ & $4(22.2)$ \\
\hline 4 or more hours/day & 0 & $2(11.1)$ \\
\hline Age & $35.0(12.5 ; 19-51)$ & $30.3(11.8 ; 18-52)$ \\
\hline Baseline 25(OH)D (nmol/L) & $76.4(27.3 ; 36-132)$ & $60.5(13.9 ; 32-78)$ \\
\hline
\end{tabular}


Table 2 Treatment predicting infection hazard, infection duration and infection severity

\begin{tabular}{|c|c|c|c|c|c|}
\hline & & All infections & Infections seen in clinic & All URTIs & URTIs seen in clinic \\
\hline & & $\begin{array}{l}n=98 \text { (54 placebo; } \\
44 \text { treatment) }\end{array}$ & $\begin{array}{l}n=63 \text { ( } 34 \text { placebo; } \\
29 \text { treatment) }\end{array}$ & $\begin{array}{l}n=68 \text { ( } 32 \text { placebo; } \\
36 \text { treatment) }\end{array}$ & $\begin{array}{l}n=55 \text { ( } 28 \text { placebo; } \\
27 \text { treatment })\end{array}$ \\
\hline \multirow[t]{3}{*}{ Infection hazard (HR $(95 \% \mathrm{Cl}))$} & Placebo & 1.00 [reference] & 1.00 [reference] & 1.00 [reference] & 1.00 [reference] \\
\hline & Treatment & $0.83(0.53,1.31)$ & $0.86(0.50,1.50)$ & $1.11(0.75,1.65)$ & $0.98(0.59,1.63)$ \\
\hline & & $P=0.42$ & $P=0.60$ & $P=0.62$ & $P=0.94$ \\
\hline \multirow{3}{*}{$\begin{array}{l}\text { Infection duration } \\
\text { (coefficient }(95 \% \mathrm{Cl}) \text { ) }\end{array}$} & Placebo & $3.05(2.35,3.76)$ & $4.15(2.77,5.53)$ & $4.87(3.29,6.45)$ & $5.28(3.38,7.18)$ \\
\hline & Treatment & $+1.04(-0.25,2.32)$ & $+1.64(-0.83,4.11)$ & $+0.51(-1.80,2.81)$ & $+0.83(-2.05,3.70)$ \\
\hline & & $P=0.11$ & $P=0.19$ & $P=0.67$ & $P=0.57$ \\
\hline \multirow{3}{*}{$\begin{array}{l}\text { Maximum infection symptom } \\
\text { severity (coefficient }(95 \% \mathrm{CI}) \text { ) }\end{array}$} & Placebo & $2.19(1.81,2.57)$ & $2.19(1.69,2.70)$ & $2.41(1.89,2.93)$ & $2.42(1.85,3.00)$ \\
\hline & Treatment & $+0.08(-0.49,0.65)$ & $+0.19(-0.58,0.95)$ & $+0.03(-0.69,0.76)$ & $-0.05(-0.85,0.76)$ \\
\hline & & $P=0.79$ & $P=0.63$ & $P=0.93$ & $P=0.91$ \\
\hline \multirow{3}{*}{$\begin{array}{l}\text { Total infection severity } \\
\text { (coefficient }(95 \% \mathrm{Cl}) \text { ) }\end{array}$} & Placebo & $12.26(7.90,16.62)$ & $20.34(9.01,31.67)$ & $25.47(11.51,39.43)$ & $29.34(12.28,46.40)$ \\
\hline & Treatment & $+2.20(-5.09,9.49)$ & $+5.95(-13.15,25.05)$ & $-3.89(-21.83,14.06)$ & $-2.87(-25.70,19.96)$ \\
\hline & & $P=0.55$ & $P=0.54$ & $P=0.67$ & $P=0.81$ \\
\hline \multirow{3}{*}{$\begin{array}{l}\text { Average daily total infection } \\
\text { symptom severity } \\
\text { (coefficient }(95 \% \text { Cl)) }\end{array}$} & Placebo & $4.00(3.25,4.75)$ & $4.74(3.52,5.96)$ & $5.28(3.73,6.82)$ & $5.41(3.81,7.02)$ \\
\hline & Treatment & $-0.26(-1.34,0.82)$ & $-0.22(-1.97,1.52)$ & $-1.08(-3.00,0.85)$ & $-0.91(-2.98,1.16)$ \\
\hline & & $P=0.64$ & $P=0.80$ & $P=0.27$ & $P=0.39$ \\
\hline
\end{tabular}

Infection hazard results are presented as $\mathrm{HR}(95 \% \mathrm{Cl})$. Results for infection duration and severity are reported as geometric mean infection severity $(95 \% \mathrm{Cl})$ and then coefficient relative to the placebo group $(95 \% \mathrm{Cl})$. Note: a greater infection severity score or greater infection duration means a more severe infection or longer duration, respectively.

Table 3 Treatment predicting infections, for all persons and among those deficient in $25(\mathrm{OH}) \mathrm{D}$ at baseline at varying thresholds

\begin{tabular}{|c|c|c|c|c|c|c|c|}
\hline & & & \multirow{2}{*}{$\begin{array}{l}\text { Number of participants } \\
\text { with baseline } 25(\mathrm{OH}) \mathrm{D} \\
\text { at level specified }(\%)\end{array}$} & \multicolumn{2}{|l|}{ All infections } & \multicolumn{2}{|c|}{ Infections seen in clinic } \\
\hline & & & & Unadjusted & Adjusted $^{a}$ & Unadjusted & Adjusted $^{\mathrm{a}}$ \\
\hline \multirow[t]{3}{*}{ All persons } & & Placebo & $16(47.1)$ & 1.00 [reference] & 1.00 [reference] & 1.00 [reference] & 1.00 [reference] \\
\hline & & & & $0.83(0.53,1.31)$ & $0.80(0.50,1.30)$ & $0.86(0.50,1.50)$ & $0.87(0.52,1.46)$ \\
\hline & & Treatment & $18(52.9)$ & $P=0.42$ & $P=0.37$ & $P=0.60$ & $P=0.60$ \\
\hline \multirow[t]{12}{*}{ 25(OH)D threshold (nmol/L) } & $\leq 40$ & Placebo & $2(50.0)$ & 1.00 [reference] & 1.00 [reference] & 1.00 [reference] & 1.00 [reference] \\
\hline & & Treatment & $2(50.0)$ & $0.56(0.32,0.96)^{b}$ & $0.41(0.22,0.78)^{b}$ & $0.27(0.07,1.00)^{b}$ & $0.26(0.06,1.17)$ \\
\hline & & & & $P=0.036^{\mathrm{b}}$ & $P=0.007^{b}$ & $P=0.050^{\mathrm{b}}$ & $P=0.079$ \\
\hline & $\leq 50$ & Placebo & $4(50.0)$ & 1.00 [reference] & 1.00 [reference] & 1.00 [reference] & 1.00 [reference] \\
\hline & & Treatment & $4(50.0)$ & $0.61(0.38,0.98)^{b}$ & $0.68(0.34,1.34)$ & $0.48(0.18,1.30)$ & $0.57(0.18,1.78)$ \\
\hline & & & & $P=0.043^{b}$ & $P=0.27$ & $P=0.15$ & $P=0.34$ \\
\hline & $\leq 60$ & Placebo & $4(40.0)$ & 1.00 [reference] & 1.00 [reference] & 1.00 [reference] & 1.00 [reference] \\
\hline & & Treatment & $6(60.0)$ & $0.86(0.54,1.35)$ & $1.02(0.60,1.72)$ & $0.66(0.34,1.30)$ & $0.74(0.36,1.56)$ \\
\hline & & & & $P=0.50$ & $P=0.95$ & $P=0.23$ & $P=0.43$ \\
\hline & $\leq 70$ & Placebo & $5(29.4)$ & 1.00 [reference] & 1.00 [reference] & 1.00 [reference] & 1.00 [reference] \\
\hline & & Treatment & 12 (70.6) & $0.80(0.51,1.25)$ & $0.82(0.48,1.41)$ & $0.95(0.46,1.97)$ & $0.85(0.42,1.70)$ \\
\hline & & & & $P=0.33$ & $P=0.48$ & $P=0.89$ & $P=0.64$ \\
\hline
\end{tabular}

Results are presented as $\mathrm{HR}(95 \% \mathrm{Cl})$.

25(OH)D 25-hydroxyvitamin D, $\mathrm{nmol} / \mathrm{L}$ nanomoles per litre.

${ }^{a}$ Analyses adjusted for age, sex, ever smoking and days per week engaging in vigorous physical activity.

${ }^{b}$ Statistically significant. 


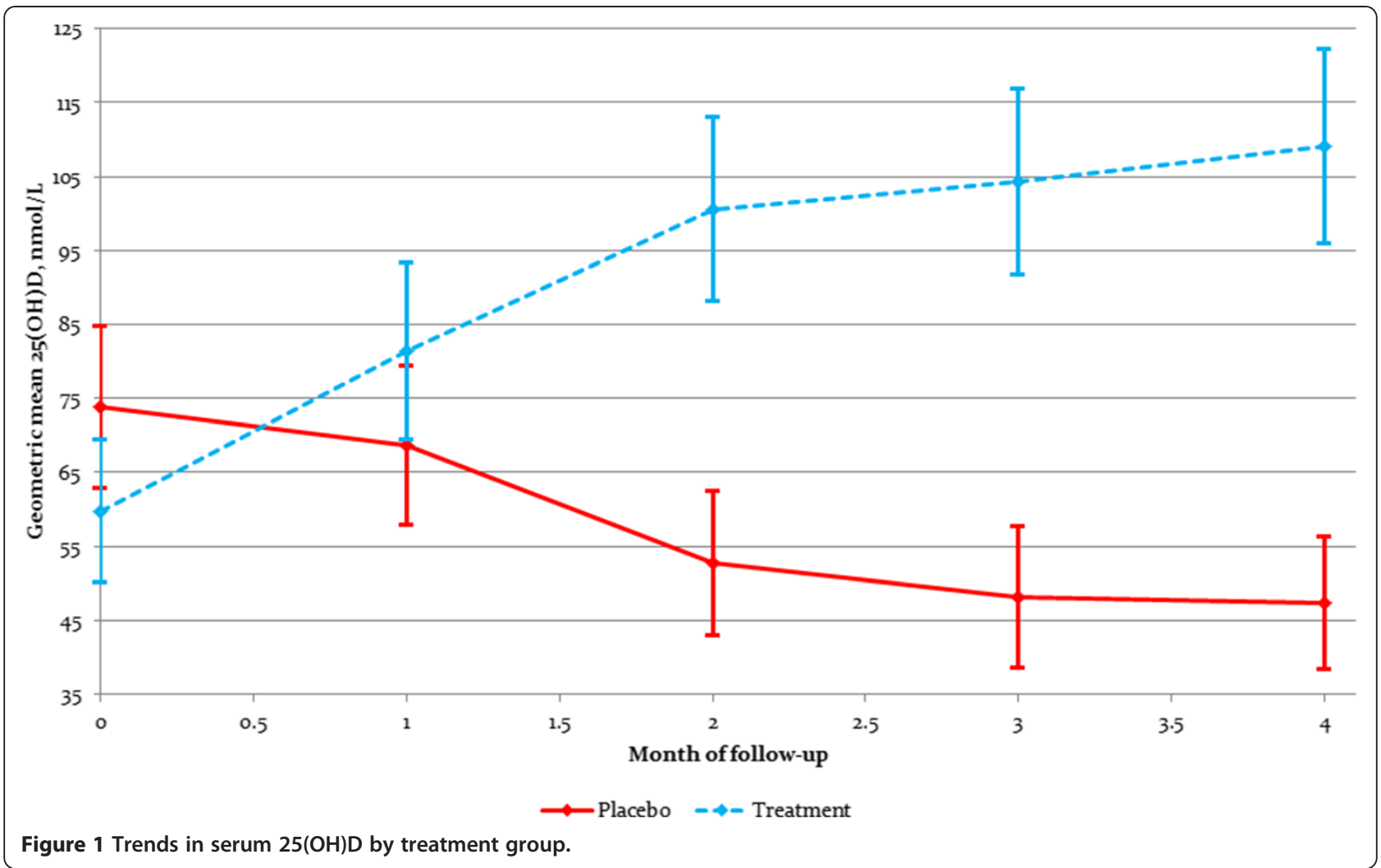

such that those of lower BMI $(<24.9)$ realised a significant increase in 25(OH)D (mean increase: 30.0; 95\% CI: $15.2,44.8 ; P=0.001)$, while those of higher BMI (25.029.9) realised a 21.2 increase (95\% CI: 7.3, 35.0; $P=0.003)$, and those of the highest BMI (30 or greater) did not have a significant increase in their $25(\mathrm{OH}) \mathrm{D}$ from treatment (mean increase: 12.9 ; 95\% CI: $-14.6,40.4 ; P=0.36$ ). While not statistically significant (test for difference: $P=0.40$ ), the difference was appreciable and persisted on adjustment for age, sex and physical activity.

Interestingly, there was also a significant positive interaction between sex and treatment in predicting $25(\mathrm{OH}) \mathrm{D}$, such that females realised nearly three times greater 25(OH)D from treatment (mean increase: 36.7; 95\% CI: 23.0, 50.5; $P<0.001$ ) than males (mean increase: 12.5 ; $95 \%$ CI: $-3.4,28.5 ; P=0.12$ ) (test for difference: $P=0.04$ ), despite virtually identical levels by sex among those on placebo. This effect persisted on adjustment for age, physical activity and BMI.

\section{Adverse events}

No participants suffered from hypercalcemia or hyperphosphatemia as determined by blood test. No participants reported any symptoms indicative of adverse events.

\section{Treatment guess}

There was no evidence of loss of blinding (data not shown).

\section{Discussion}

In this pilot $\mathrm{RCT}$, we have shown evidence of a protective effect of 20,000 IU/week cholecalciferol supplementation against acute infection among persons who were vitamin $\mathrm{D}$ deficient at baseline. Treatment realised significantly higher $25(\mathrm{OH}) \mathrm{D}$ compared to placebo. While no significant effect of treatment on infection was seen in the aggregate, among those who were vitamin D deficient at the start of the study, a significant protective effect from treatment was evident. Importantly, the magnitude of effect was enhanced on restriction to infections which were assessed in clinic, and associations disappeared on adjustment for serum 25(OH)D. A similar but less consistent interaction by level of baseline $25(\mathrm{OH}) \mathrm{D}$ was seen for infection severity. No treatment effect on infection duration was found. None of our cohort members experienced adverse effects, and the highest $25(\mathrm{OH}) \mathrm{D}$ was $154 \mathrm{nmol} / \mathrm{L}$. Since our cohort was comprised of healthy adults in a Western nation, its generalisability extends to similarly situated Western healthy adults.

While no effect of treatment is apparent in the aggregate, a significant protective effect was present among those who were vitamin D deficient at baseline. This effect among the deficient is similar to a trial of vitamin D supplementation as an intervention against exacerbations of COPD, which found efficacy only among those with $25(\mathrm{OH}) \mathrm{D}<25 \mathrm{nmol} / \mathrm{L}$ [24]. Ours is the first trial of 
cholecalciferol supplementation showing this effect for acute infections in vitamin D-deficient healthy adults. Murdoch and colleagues examined their infection analyses by level of baseline $25(\mathrm{OH}) \mathrm{D}$ of $50 \mathrm{nmol} / \mathrm{L}$ but reported no significant interactions [20]. Rees and colleagues also examined treatment effect by level of baseline 25(OH)D but found no protective effect among the deficient, though this may be due to the low dose used in that trial (1,000 IU/day) [19].

The protective effect on acute infection was clearest and most pronounced for infection risk. A similar but less consistent effect was seen for infection severity. The inconsistency of the trends of associations may indicate that no association exists with severity. However, severity was necessarily reported by participants, and the variability between participants as to what is severe no doubt affected the quality of the measure.

While no effect of treatment was evident for infection duration, this is not unexpected. Our hypothesis was that vitamin $\mathrm{D}$ enables the effective responsiveness of innate immune system pathways and thus improves the ability of the body to block the colonisation by pathogens [4,25-30], so an effect of vitamin $\mathrm{D}$ on absolute infection risk was expected. Vitamin D also has the capacity to depress inflammatory immune pathways like IP-10 and IL-8 [31,32], enabling an effective but less inflammatory response. Thus, an effect on infection severity is expected from vitamin D sufficiency. Once a pathogen has already secured a hold, however, the duration of infection is a function of the efficiency of the immune response and the characteristics of the aetiologic pathogen and thus more independent of vitamin D status.

On evaluating the impact of treatment on serum $25(\mathrm{OH}) \mathrm{D}$, some interesting differences were seen by level of BMI and by sex, such that treatment was less impactful on $25(\mathrm{OH}) \mathrm{D}$ among those of higher BMI, while females had a greater increase in $25(\mathrm{OH}) \mathrm{D}$ from treatment. The difference by BMI is not surprising, given the vitamin $\mathrm{D}$ hoarding of adipose tissue would keep serum 25(OH)D lower than might occur in those of lower BMI [33,34], and others have demonstrated this as well [35]. However, the difference by sex was unexpected and not easily explained. Certainly, it is possible that females have a differential vitamin D metabolism than males, as has been demonstrated by others [36].

Our study's methodology compares favourably with many of those undertaken previously. We designed our method to improve upon the designs reported in publications prior to when we undertook our study $[14,18]$, which relied on passive detection. Our use of daily online followup to detect infections as close to the start of infection as possible, followed by objective assessment, was designed to allow an accurate and sensitive detection, while not affecting adherence. These methods are similar to that of
Murdoch and colleagues [20] and to a lesser extent that of Rees and colleagues; however, these still relied on participant reporting. By placing the onus for detection on the study investigators, more infections may be detected closer to symptom onset. By relying on participants to report symptoms via daily questionnaire, the subjective nature of what is a reportable symptom is still a limitation.

Our hypothesis that vitamin D enhances the efficiency of the innate immune system to block colonisation by pathogens could not be evaluated due to the absence of pathogen sampling data. This is a limitation since it precluded our evaluation of pathogens present during infection or validation of infectious aetiology of symptoms. Further to this, our not obtaining valid nasal swab data to assess the aetiological pathogen and substantiate infection symptoms as a true infection is a limitation. The high frequency of infections during the study may indicate that some of the infections reported, particularly those not assessed in clinic, were not true infections. However, that we saw a potentiation in the treatment effect among the deficient on restricting to infections seen in clinic is supportive of a true effect, as this necessarily removes some symptoms which were not true infections. Another limitation is that our greatest impact of treatment was among a subgroup with only four people. While they comprised an appreciable proportion of our cohort $(11.8 \%)$, this is nonetheless a small number. However, in addition to the statistical significance of this association, we think that the attenuation in association as the threshold of sufficiency is raised and that the treatment effect is enhanced on restriction to infections assessed in clinic are supportive of a true association, rather than artifact. Another measure that would have strengthened this study was to measure levels of activated vitamin D and antimicrobial peptides in the respiratory tract, which would have helped support the causality of a treatment effect. Finally, a small number $(n=3$; two treatment, one placebo) reported taking multivitamins during the study, while four participants (all on placebo) started taking fish oil during the study (two at week 1 , one at week 3 , one at week 13), none of whom were also taking multivitamins. Consequently, there was some nontreatment supplementation of vitamin $\mathrm{D}$, though of a relatively minor level (400 to $1,000 \mathrm{IU})$. Given the preponderance of fish oil use among controls, any impact of this would have been to reduce the difference in serum $25(\mathrm{OH}) \mathrm{D}$ over time, a reduction that if present was quite small indeed. Moreover, if there was a reduction in the spread of serum 25(OH)D between treatment arms, then potentially the observed reductions in infection risk may be an underestimate.

\section{Conclusions}

Our results from this pilot trial of weekly cholecalciferol supplementation vs. placebo among a cohort of 34 healthy 
adults suggest a significant protective effect of treatment against acute infection risk among those which started the study vitamin $\mathrm{D}$ deficient. This effect persisted on adjustment for potential confounders, and the trends found on raising the threshold of deficiency/sufficiency and on restricting to infections seen in clinic are suggestive of a true effect. A larger study is needed to validate these results, and graded doses of supplementation are necessary to delineate the most optimal dose to realise a reduction in acute infection risk.

\section{Additional files}

Additional file 1: CONSORT 2010 checklist of information to include
when reporting a randomised trial.
Additional file 2: CONSORT 2010 flow diagram.
Additional file 3: Treatment predicting symptom severity for
infections seen in clinic, for all persons and among those deficient
in 25(OH)D at baseline at varying thresholds. This supplemental table
provides in detail the results for the three metrics of infection severity
(maximum reported infection symptom severity for that infection,
average daily total infection symptom severities, total sum of infection
severity scores for all infection symptoms for each day of the infection
and summated these for a total infection severity score) and stratified
analyses by level of vitamin D sufficiency.

\section{Abbreviations}

25(OH)D: 25-hydroxyvitamin D; BMI: Body mass index; CIPRIS: Cholecalciferol Intervention to Prevent Respiratory Infections Study; IU: International unit; nmol/L: Nanomoles per litre; RCT: Randomised controlled trial;

$\mathrm{RTI}$ : Respiratory tract infection.

\section{Competing interests}

The authors declare that they have no competing interests.

\section{Authors' contributions}

The project was conceived and developed by SSJ, with the assistance of NS, BT, LB and IvdM. Funding was obtained by SSJ, NS, BT, LB and IvdM. The project was administered by SSJ. Statistical analysis was undertaken by SSJ, with the assistance of LB. Some additional analyses were undertaken by PT, including the development of participant correspondence letters reporting biological parameter tracking during the study follow-up. The initial manuscript draft was composed by SSJ, with the assistance of all authors in the revision process. All authors were involved in the critical revision of the manuscript and approved it for submission. SSJ had full access to all the data in the study and takes responsibility for the integrity of the data and the accuracy of the analysis. Any persons interested in obtaining a copy of the trial protocol can do so by contacting SSJ.

\section{Acknowledgements}

This study was funded by a grant from the Royal Hobart Hospital Research Foundation. SSJ is supported by a Multiple Sclerosis Research Australia Postdoctoral Research Fellowship. IvdM is supported by an Australian Research Council Future Fellowship. We would like to thank our study nurse, Roxanne Maher, and our data entry specialist, Carol Hurst.

\section{Author details}

'Menzies Institute for Medical Research, University of Tasmania, 17 Liverpool Street, Hobart, TAS, Australia. ${ }^{2}$ School of Pharmacy, University of Tasmania, Hobart, Australia. ${ }^{3}$ School of Medicine, University of Tasmania, Hobart, Australia.

Received: 16 September 2014 Accepted: 11 December 2014 Published: 9 March 2015

\section{References}

1. Glezen WP, Greenberg SB, Atmar RL, Piedra PA, Couch RB. Impact of respiratory virus infections on persons with chronic underlying conditions. JAMA. 2000;283(4):499-505.

2. Treanor J, Falsey A. Respiratory viral infections in the elderly. Antiviral Res. 1999:44(2):79-102.

3. Fendrick AM, Monto AS, Nightengale B, Sarnes M. The economic burden of non-influenza-related viral respiratory tract infection in the United States. Arch Intern Med. 2003;163(4):487-94.

4. Beard JA, Bearden A, Striker R. Vitamin D and the anti-viral state. J Clin Virol. 2011;50(3):194-200.

5. Sun J. Vitamin D and mucosal immune function. Curr Opin Gastroenterol. 2010;26(6):591-5.

6. Engelsen $\mathrm{O}$, Brustad M, Aksnes L, Lund E. Daily duration of vitamin D synthesis in human skin with relation to latitude, total ozone, altitude, ground cover, aerosols and cloud thickness. Photochem Photobiol. 2005;81(6):1287-90.

7. Kimlin MG, Lucas RM, Harrison SL, van der Mei I, Armstrong BK, Whiteman $D C$, et al. The contributions of solar ultraviolet radiation exposure and other determinants to serum 25-hydroxyvitamin D concentrations in Australian adults: the AusD study. Am J Epidemiol. 2014;179(7):864-74

8. Laaksi I, Ruohola JP, Tuohimaa P, Auvinen A, Haataja R, Pihlajamaki H, et al. An association of serum vitamin $D$ concentrations $<40 \mathrm{nmol} / \mathrm{L}$ with acute respiratory tract infection in young Finnish men. Am J Clin Nutr. 2007:86(3):714-7.

9. Ginde AA, Mansbach JM, Camargo Jr CA. Association between serum 25-hydroxyvitamin D level and upper respiratory tract infection in the third national health and nutrition examination survey. Arch Intern Med. 2009;169(4):384-90.

10. McNally JD, Leis K, Matheson LA, Karuananyake C, Sankaran K, Rosenberg AM. Vitamin D deficiency in young children with severe acute lower respiratory infection. Pediatr Pulmonol. 2009;44(10):981-8.

11. Roth DE, Shah R, Black RE, Baqui AH. Vitamin D status and acute lower respiratory infection in early childhood in Sylhet. Bangladesh Acta Paediatr. 2010;99(3):389-93.

12. Sabetta JR, DePetrillo P, Cipriani RJ, Smardin J, Burns LA, Landry ML. Serum 25-hydroxyvitamin $D$ and the incidence of acute viral respiratory tract infections in healthy adults. PLoS One. 2010;5(6):e11088.

13. Wayse V, Yousafzai A, Mogale K, Filteau S. Association of subclinical vitamin $D$ deficiency with severe acute lower respiratory infection in Indian children under 5 y. Eur J Clin Nutr. 2004;58(4):563-7.

14. Laaksi I, Ruohola JP, Mattila V, Auvinen A, Ylikomi T, Pihlajamaki H. Vitamin D supplementation for the prevention of acute respiratory tract infection: a randomized, double-blinded trial among young Finnish men. J Infect Dis. 2010;202(5):809-14.

15. Urashima M, Segawa T, Okazaki M, Kurihara M, Wada Y, Ida H. Randomized trial of vitamin D supplementation to prevent seasonal influenza $A$ in schoolchildren. Am J Clin Nutr. 2010;91(5):1255-60.

16. Camargo Jr CA, Ganmaa D, Frazier AL, Kirchberg FF, Stuart JJ, Kleinman K, et al. Randomized trial of vitamin $D$ supplementation and risk of acute respiratory infection in Mongolia. Pediatrics. 2012;130(3):e561-7.

17. Bergman $P$, Norlin AC, Hansen S, Rekha RS, Agerberth B, Bjorkhem-Bergman $L$, et al. Vitamin D3 supplementation in patients with frequent respiratory tract infections: a randomised and double-blind intervention study. BMJ Open. 2012;2:6.

18. Li-Ng M, Aloia JF, Pollack S, Cunha BA, Mikhail M, Yeh J, et al. A randomized controlled trial of vitamin D3 supplementation for the prevention of symptomatic upper respiratory tract infections. Epidemiol Infect. 2009;137(10):1396-404.

19. Rees JR, Hendricks K, Barry EL, Peacock JL, Mott LA, Sandler RS, et al. Vitamin D3 supplementation and upper respiratory tract infections in a randomized, controlled trial. Clin Infect Dis. 2013;57(10):1384-92.

20. Murdoch DR, Slow S, Chambers ST, Jennings LC, Stewart AW, Priest PC, et al. Effect of vitamin D3 supplementation on upper respiratory tract infections in healthy adults: the VIDARIS randomized controlled trial. JAMA. 2012;308(13):1333-9.

21. Jolliffe DA, Griffiths CJ, Martineau AR. Vitamin D in the prevention of acute respiratory infection: systematic review of clinical studies. J Steroid Biochem Mol Biol. 2013;136:321-9.

22. Bergman $P$, Lindh $A U$, Bjorkhem-Bergman $L$, Lindh JD. Vitamin $D$ and respiratory tract infections: a systematic review and meta-analysis of randomized controlled trials. PLoS One. 2013;8(6):e65835. 
23. Prentice RL, Williams $B J$, Peterson $A V$. On the regression analysis of multivariate failure time data. Biometrika. 1981;68(2):373-9.

24. Lehouck A, Mathieu C, Carremans C, Baeke F, Verhaegen J, Van Eldere J, et al. High doses of vitamin $D$ to reduce exacerbations in chronic obstructive pulmonary disease: a randomized trial. Ann Intern Med. 2012;156(2):105-14.

25. Liu PT, Stenger S, Li H, Wenzel L, Tan BH, Krutzik SR, et al. Toll-like receptor triggering of a vitamin D-mediated human antimicrobial response. Science. 2006;311(5768):1770-3.

26. Schauber J, Dorschner RA, Coda AB, Buchau AS, Liu PT, Kiken D, et al. Injury enhances TLR2 function and antimicrobial peptide expression through a vitamin D-dependent mechanism. J Clin Invest. 2007;117(3):803-11.

27. Schauber J, Dorschner RA, Yamasaki K, Brouha B, Gallo RL. Control of the innate epithelial antimicrobial response is cell-type specific and dependent on relevant microenvironmental stimuli. Immunology. 2006;118(4):509-19.

28. Scherberich JE, Kellermeyer M, Ried C, Hartinger A. 1-alpha-Calcidol modulates major human monocyte antigens and toll-like receptors TLR 2 and TLR4 in vitro. Eur J Med Res. 2005;10(4):179-82.

29. Wang TT, Nestel FP, Bourdeau V, Nagai Y, Wang Q, Liao J, et al. Cutting edge: 1,25-dihydroxyvitamin D3 is a direct inducer of antimicrobial peptide gene expression. J Immunol. 2004;173(5):2909-12.

30. Zasloff M. Inducing endogenous antimicrobial peptides to battle infections. Proc Natl Acad Sci U S A. 2006;103(24):8913-4.

31. Hansdottir S, Monick MM, Lovan N, Powers L, Gerke A, Hunninghake GW Vitamin $D$ decreases respiratory syncytial virus induction of NF-kappaB-linked chemokines and cytokines in airway epithelium while maintaining the antiviral state. J Immunol. 2010;184(2):965-74.

32. McNally P, Coughlan C, Bergsson G, Doyle M, Taggart C, Adorini L, et al. Vitamin $D$ receptor agonists inhibit pro-inflammatory cytokine production from the respiratory epithelium in cystic fibrosis. J Cyst Fibros. 2011;10(6):428-34.

33. Blum M, Dolnikowski G, Seyoum E, Harris SS, Booth SL, Peterson J, et al. Vitamin D(3) in fat tissue. Endocrine. 2008;33(1):90-4.

34. Zittermann A, Ernst JB, Gummert JF, Borgermann J. Vitamin D supplementation, body weight and human serum 25-hydroxyvitamin D response: a systematic review. Eur J Nutr. 2014;53(2):367-74.

35. Aguirre Castaneda R, Nader N, Weaver A, Singh R, Kumar S. Response to vitamin D3 supplementation in obese and non-obese Caucasian adolescents. Horm Res Paediatr. 2012;78(4):226-31.

36. Correale J, Ysrraelit MC, Gaitan MI. Gender differences in 1,25 dihydroxyvitamin D3 immunomodulatory effects in multiple sclerosis patients and healthy subjects. J Immunol. 2010;185(8):4948-58.

doi:10.1186/2055-0928-1-7

Cite this article as: Simpson et al: Weekly cholecalciferol supplementation results in significant reductions in infection risk among the vitamin D deficient: results from the CIPRIS pilot RCT. BMC Nutrition 2015 1:7.

\section{Submit your next manuscript to BioMed Central and take full advantage of:}

- Convenient online submission

- Thorough peer review

- No space constraints or color figure charges

- Immediate publication on acceptance

- Inclusion in PubMed, CAS, Scopus and Google Scholar

- Research which is freely available for redistribution 